\title{
Depoimento sem dano: Dissidências e concordâncias na inquirição de crianças e adolescentes
}

\author{
No damage deposition: Dissents and concurrences in the hearing of children and adolescents
}

Ana Paula Machado ${ }^{[a]}$, Dorian Mônica Arpini ${ }^{[b]}$

\footnotetext{
[a] Psicóloga graduada pela Universidade Federal de Santa Maria (UFSM), pós-graduanda no Programa de Pós-Graduação da Universidade Comunitária da Região de Chapecó (UnoChapecó) no curso Proteção de Direitos e Trabalho em Rede, psicóloga do Centro de Referência Especializado da Assistência Social (CREAS) da cidade de Chapecó, SC - Brasil, e-mail: psicomaninha@hotmail.com

${ }^{[b]}$ Psicóloga, doutora em Psicologia Social pela Pontifícia Universidade Católica de São Paulo (PUC-SP), professora associada do Departamento de Psicologia e do Programa de Pós-Graduação em Psicologia da Universidade Federal de Santa Maria (UFSM), Santa Maria, RS Brasil, e-mail: monica.arpini@ gmail.com
}

Recebido: 23/05/2011 Received: 05/23/2011

Aprovado: 29/11/2011 Approved: 11/29/2011

\begin{abstract}
Resumo
Este artigo aborda a percepção de profissionais de Direito, Psicologia e Serviço Social acerca do projeto de lei n. 35/2007, intitulado "Depoimento sem Dano" (DSD). Objetivou-se levantar junto aos profissionais a quem compete a execução do projeto suas opiniões, ideias e argumentos sobre a inquirição de crianças e adolescentes vítimas de violência. Foi realizado um estudo qualitativo, com a utilização da técnica de entrevistas semidirigidas. A análise dos dados foi realizada através da análise de conteúdo. Os resultados identificaram aspectos sobre o desenvolvimento do trabalho com o DSD, o olhar dos profissionais que trabalham na área, a percepção quanto à especificidade profissional dentro da proposta, e ainda, a compreensão de que o DSD se insere num momento de valorização da infância e das problemáticas a ela associadas. Conclui-se que a percepção dos profissionais que estão inseridos no contexto jurídico e executam o Depoimento sem Dano diferem das opiniões dos profissionais que criticam a proposta; sendo necessário manter um diálogo entre as partes.
\end{abstract}

Palavras-chave: Violência contra crianças. Abuso da criança. Infância. Psicologia jurídica.

\begin{abstract}
This paper shows, through a qualitative analysis, the direct perception of professionals, psychology and social work on the bill n. 35/2007, entitled "No Damage Deposition" (NDD). The objective was to investigate with professionals who are responsible for the implementation of the project their views, ideas and arguments on the hearing of children and adolescents victims of violence. We conducted a qualitative study, using the technique of semi-directed interviews. Data analysis was performed using content analysis. The results identified aspects on the development aspects of working with NDD, the eyes of professionals working in the area, the perception about the professional specificity in the proposal, and also the understanding that the NDD is part of a recovery time of childhood and the problems associated with it. We conclude that the perception of professionals that are part of the legal and running "No Damage Deposition" differ from the opinions of professionals who criticize the proposal, being necessary to maintain a dialogue between the parties.
\end{abstract}

Keywords: Violence against children. Child abuse. Childhood. Forensic psychology. 


\section{Introdução}

Diante dos inúmeros constrangimentos, mal-estares e relatos apresentados por crianças e adolescentes vítimas de abuso sexual na presença dos operadores do Direito durante a audiência judicial, um grupo de magistrados do Rio Grande do Sul buscou repensar a maneira pela qual era feita a abordagem de inquirição em juízo dessas vítimas. No ano de 2003, passou a ser utilizado no Juizado da Infância e Juventude de Porto Alegre o projeto de lei "Depoimento sem Dano" (DSD). Esse projeto visa realizar a escuta judicial de crianças e adolescentes num ambiente mais receptivo, de maneira que o depoimento possa ser colhido por técnicos capacitados em abordar a questão do abuso sexual de forma especializada tendo em vista as especificidades das condições de desenvolvimento.

Para tanto, a colhida do depoimento acontece em uma sala adaptada, onde a criança/adolescente é inquirida por um psicólogo ou assistente social sem a presença dos operadores jurídicos e de seu suposto agressor. As perguntas feitas à vítima são realizadas pelos profissionais designados, o testemunho é assistido pelos operadores de Direito utilizando-se câmeras e recursos de áudio; o depoimento fica gravado, podendo ser acessado durante o andamento do processo e evitando que a criança/adolescente tenha de repetir seu testemunho.

$\mathrm{Na}$ apresentação de seu objetivo, o projeto de lei atende a dois princípios: a redução do dano durante a produção de provas em processos judiciais, nos quais a criança/adolescente é vítima ou testemunha de abusos sexuais, e em segundo, a garantia dos direitos da criança/adolescente, quanto a ser ouvida em juízo, bem como sua palavra ser valorizada e a inquirição respeitar sua condição de pessoa em desenvolvimento. Além disso, o projeto salienta que a normativa processual vigente (criminal e civil) trata de forma geral a produção de prova realizada em juízo, não oportunizando assim, em momento algum, modelos diferentes para inquirir crianças/adolescentes.

De acordo com Santos e Gonçalves (2008), que realizaram um levantamento das culturas e práticas não revitimizantes na tomada de depoimentos especiais, o Brasil caminha para uma busca por metodologias de inquirição alternativas que minimizem os efeitos prejudiciais que o depoimento nos moldes anteriores ao projeto de lei provocava. Segundo os autores, essas experiências permitem concluir que o processo penal está se modificando em várias partes do mundo, uma vez que esse tipo de inquirição já ocorre em outros países. Destaca ainda, o fato de a proposta oportunizar que o trabalho aconteça de forma interdisciplinar incluindo as áreas do Direito, da Psicologia e do Serviço Social.

Em relação a esse aspecto, Santos e Gonçalves (2008) reconhecem que o entendimento e desenvolvimento da colhida e outiva de testemunho não se limita a uma categoria científica e/ou profissional; percorrendo e somando-se visões distintas, que, em conjunto, proporcionam um saber mais enriquecido, eficaz e ampliado. E, finalmente, chamam atenção para que essas formas alternativas de ouvir crianças e adolescentes em juízo possam ser utilizadas como subsídio para a formulação de políticas de enfrentamento da violência sexual infantil.

A respeito do posicionamento e desempenho do profissional que exercerá a escuta judicial de crianças e adolescentes, Eliachef (2007) afirma que os mesmos deveriam se perguntar se o que eles pensam dizer expressa bem a posição que ocupam em relação à criança/adolescente; isso implica que esse papel tenha sido claramente definido. Pois, as posições simbólicas que os profissionais ocupam em relação às vítimas têm como efeito limitar o que temos a lhes dizer.

Por isso, na elaboração do projeto de lei, Cezar (2008) atenta para o papel exercido pelo técnico durante a oitiva do depoimento, devendo este possuir um conhecimento teórico relativo à dinâmica do abuso, preferencialmente com experiência em perícias, pensamento hábil e articulado que permita a fácil compreensão e interação de todos que estão a participar do ato judicial; e ainda, complementa que o profissional deva ser capaz de reproduzir aspectos de base segura, acolhedora e continente, bem como transparecer um sentimento de compreensão com a situação em que a criança/ adolescente está inserida.

Dentro da proposta do projeto de lei, a indicação de quais profissionais seriam indicados para ouvir o testemunho da vítima estão incluídos os psicólogos e assistentes sociais que atuam dentro do sistema judiciário. Decorrente dessas indicações houve manifestações de apoio e critica ao projeto. Sendo assim, no presente trabalho serão apresentadas algumas das manifestações que apoiam e sustentam a defesa do DSD, bem como aquelas que criticam e rejeitam a proposta. 


\section{As concordâncias}

De acordo com informações expostas no projeto de lei, na Convenção Internacional sobre os Direitos da Criança, como também em dispositivos presentes no Estatuto da Criança e Adolescente (ECA/2005) autorizam crianças e adolescentes (como sujeitos de direitos) a testemunhar, como forma de valorizar sua palavra; respeitando, contudo, suas limitações desenvolvimentais. Tais circunstâncias não impedem que o juiz nomeie a criança/adolescente que preste esclarecimento sobre o fato apenas como informante, podendo suas declarações ser analisadas em conjunto com as demais provas judiciais; inexistindo, assim, uma hierarquia entre as provas produzidas no decorrer do processo.

Goodman (2008) defende que a literatura existente não oferece suporte para a hipótese segundo a qual o testemunho colhido por meio de entrevistas gravadas ou via Closed Circuit of Television (CCTV) reduza a exatidão do depoimento em comparação com a confrontação presencial no tribunal. Em muitos casos a confrontação face a face pode dificultar em vez de facilitar a capacidade e a vontade da criança/ adolescente de prestar um depoimento completo e preciso.A autora ainda complementa que se a criança/ adolescente estiver suficientemente preparada em termos emocionais (incluindo respeito, adequação da abordagem à sua idade, estratégias de enfrentamento da situação), bem como, encaminhamentos após o depoimento; o comparecimento ao tribunal pode ser uma experiência potencialmente fortalecedora. As consequências que podem decorrer do seu comparecimento judicial vão depender, muito mais, de como os profissionais e a família lidam com suas necessidades emocionais durante, e após o processo.

Em manifestação favorável à proposta do DSD, Williams (s/d), afirma que o Conselho Federal de Psicologia (CFP) compara de maneira inadequada os delitos de homicídios e de abuso sexual sugerindo que se estabeleça outra forma de produção de provas, sem o depoimento da vítima; a autora ressalta que nos casos de abuso sexual infantil, de acordo com suas particularidades, na maioria das vezes não existem provas materiais, e sim apenas a palavra da criança/adolescente e do adulto ou suposto agressor. E ainda, discorda do posicionamento do Conselho Federal de Psicologia no que diz respeito à criança calar-se sobre um evento traumático, afirmando que, no mínimo, não existe consenso sobre o assunto, e destaca a técnica da prática narrativa para dessensibilizar traumas utilizando a Terapia Cognitivo-Comportamental nos casos de Transtorno do Estresse Pós-Traumático que envolve violência sexual.

A respeito da indicação de o DSD ser executado por psicólogos, Williams (s/d) discorda quanto ao fato de o CFP acreditar que o psicólogo tenha apenas um "verdadeiro papel", e não múltiplos. Ele interpreta, ainda, a proposta do projeto de lei como um avanço na busca de garantias dos direitos das crianças/ adolescentes nos tribunais, justamente por dar voz a eles quando são tolhidos de seus direitos. Em contra partida, Williams concorda com o CFP em analisar se é atribuição do psicólogo realizar o DSD, mas salienta existir um reconhecimento por parte dos Magistrados de que os profissionais da Psicologia seriam os mais indicados para exercer tal função diante das suas especificidades. Ele também entende que independentemente de quem fizer tal função, o profissional necessitará de capacitação para que não ocorram faltas éticas como de "forçar a criança a falar".

Diante do fato de a criança ou adolescente ser exposto em diferentes serviços com diferentes profissionais tendo de relatar a violência sofrida por elas, Ferrari (2009) cita o DSD como uma alternativa para diminuir o exaustivo percurso do processo legal; por meio dele o processo seria reduzido a uma única situação de investigação dentro do sistema judiciário para a obtenção antecipada de provas.

Nesse sentido, um aperfeiçoamento na proposta do projeto de lei deveria falar mais alto, evitando que a criança/adolescente fornecesse inúmeros depoimentos em diferentes serviços. Segundo Ferrari (2009), infelizmente, na prática, isso ainda está no princípio; eventuais dificuldades que os profissionais vivenciam devem-se às especificidades de cada profissão, por conta de que cada uma delas tem seu Código de Ética e sua autonomia.

\section{As dissidências}

Alguns profissionais, principalmente psicólogos, mostraram-se críticos e expuseram suas preocupações em repúdio à proposta do DSD. Em manifesto oficial, o Conselho Federal de Psicologia (2008) expôs que o projeto de lei justifica sua utilização para a produção do que poderia ser a única prova possível contra o acusado, acreditando ser uma excessiva 
valorização do depoimento da vítima; sendo que em tais casos, poderia ser prejudicial às crianças/ adolescentes que sofreram a violência sexual, pois algumas vezes as violências podem ser cometidas por pessoas que mantêm vínculos próximos a elas. 0 entendimento do CFP é o de que é sempre danoso obrigar a criança/adolescente a falar sobre o que ainda precisa calar, pois o fato não poderia ser simbolizado ainda.

Ainda, o CFP defende a ideia de que falar para elaborar uma situação traumática, em psicoterapia, é muito diferente do que falar para depor à Justiça; destacando que é necessário diferir o plano terapêutico do plano do Direito. Na manifestação apresentada pelo CFP, também se acredita ser necessário saber se a criança/adolescente deseja falar sobre o abuso sexual em juízo, deve-se assegurar à criança ou adolescente o direito de falar ou não falar sobre o fato; se assim apresentarem condições e desejo, poderão falar diretamente ao juiz.

Em sua manifestação, o CFP também defendeu que para a execução da coleta do depoimento das crianças/adolescentes vítimas de violência sexual, segundo o DSD, o psicólogo não é chamado para desempenhar o papel que a profissão exige, mas em atuar como mediador do juiz, procurando ganhar a confiança das supostas vítimas. Por fim, o Conselho Federal de Psicologia e a Comissão Nacional de Direitos Humanos sugerem que a Justiça construa outros meios de montar um processo penal e punir os acusados pelo abuso sexual de uma criança ou adolescente; acreditam que não será pelo uso de modernas tecnologias de extração de informações, com a presença de psicólogos supostamente treinados e fora de seu verdadeiro papel, que irão proteger as crianças/adolescentes abusados.

Nessa concepção a respeito do lugar ocupado pelo profissional psi segundo a proposta do projeto de lei; Souza (2007) cita a opinião da psicóloga Esther Arantes, que defende que nada identifica a prática psi nos termos do projeto, pois todos eles são próprios da prática judiciária. Na opinião da referida psicóloga, a audiência jurídica ignora as características inerentes à escuta psicológica, pois esta é orientada pelas demandas e desejos da criança/ adolescente devendo manter o sigilo profissional.
Com relação ao efeito danoso da colhida de testemunho nos moldes do DSD, Brito (2008) sustenta a inadequação da prática do projeto de lei, especialmente quando vista como atribuição de psicólogos. Em seu artigo, "Diga-me agora... O DSD em análise" ${ }^{1}$, Brito apoia e reforça a moção apresentada pelo Conselho Federal de Psicologia encaminhada ao Senado Federal em 2007 fundamentando que tal tarefa "não diz respeito à prática psicológica” (2008, p. 118).

Sobre o papel ocupado pelo assistente social em desempenhar o DSD, Brito (2008) destaca que o Conselho Federal de Serviço Social (CFSS) também compartilha da pronunciação do Conselho Federal de Psicologia, criticando a proposta de inquirição seguindo o modelo do projeto de lei. Nesse manifesto, o CFSS defende que a atuação do assistente social seria a de intérprete da fala do juiz na execução desse tipo de depoimento, não sendo uma prática pertinente ao Serviço Social.

No procedimento para a oitiva do testemunho segundo a proposta do DSD, esta se apresenta como urgência para tomada de decisão, pois se determina que num único encontro a questão deva ser elucidada, limitando-se o direito da criança/adolescente de ser ouvido/a. Com essas características, Brito (2008) acredita que não há tempo para entrevistas com responsáveis, com o suposto agressor e para estudos psicológicos acerca do caso. Ao analisar a prática da proposta do projeto de lei, Brito (2008) levanta questões como: A não vitimização da criança/adolescente ocorreria apenas pelo fato de se evitar o depoimento desta na frente do acusado e de não ser solicitado que forneça depoimento em distintas e diversas ocasiões? A menoridade jurídica de crianças e adolescentes estaria sendo desconsiderada, equiparando-se o direito de ser ouvido à obrigação de testemunhar?

Em 2009, o Conselho Federal de Psicologia, em conjunto com sua Comissão Nacional de Direitos Humanos, apresentou publicação intitulada "Falando sério sobre a escuta de crianças e adolescentes envolvidos em situação de violência e a rede de proteção". Essa proposta inclui vários textos de diversos autores (alguns citados neste trabalho) que abordam e discutem o DSD, reafirmando sua posição crítica diante da proposta do projeto de lei e reiterando questionamentos quanto à sua prática.

\footnotetext{
1 O artigo na íntegra pode ser encontrado seguindo o endereço eletrônico apresentado nas referências.
} 
Sendo assim, esta pesquisa teve por objetivo identificar a percepção que os profissionais indicados para executar do projeto de lei n. 35/2007, denominado "Depoimento sem Dano", possuem a respeito de sua prática. $\mathrm{O}$ desenvolvimento do estudo foi realizado nas dependências de uma Comarca Regional de Infância e Juventude, localizada em um município do interior do Rio Grande do Sul.

\section{Metodologia}

Este estudo possui caráter exploratório, de base qualitativa, no qual os profissionais foram entrevistados em suas salas de trabalho, onde desempenham suas funções. Foram entrevistados todos os profissionais que executam o DSD no local, sendo eles: uma psicóloga, duas assistentes sociais, e a juíza da Comarca da Infância e Juventude.

0 trabalho foi submetido e aprovado pelo Comitê de Ética e Pesquisa (CEP) da Instituição responsável pela execução da pesquisa ${ }^{2}$. Em seguida, buscou-se o acesso aos participantes de contato telefônico.

Para atingir aos objetivos propostos, a pesquisa se propôs a trabalhar com a técnica de entrevista semidirigida, permitindo maior aprofundamento da temática a ser investigada.

A escolha da técnica utilizada se sustenta pelo fato de que na entrevista semidirigida a coordenação pode ocorrer de forma alternada. 0 entrevistador oferece uma flexibilidade ao entrevistado em assumir a direção, associando ao assunto geral temas particulares, o que facilita a construção das ideias em exposição. Esse modelo de entrevista favorece ao entrevistador abordar os assuntos a serem debatidos, guiando a discussão para questões mais especificas obtendo detalhes, exemplos e contextos. Da mesma forma, o entrevistado pode discorrer sobre as questões de uma forma mais abrangente de suas ideias, experiências ou opiniões sobre o assunto (Turato, 2003).

Para facilitar o processo de realização das entrevistas, utilizou-se uma estrutura prévia com alguns eixos norteadores: a opinião a respeito do DSD; as possíveis vantagens e desvantagens segundo suas percepções; o desenvolvimento de capacitações para esses profissionais em desempenhar a atividade; dissidências dentro das categorias profissionais das quais fazem parte; percepção dessas dissidências; e percepção por parte dos profissionais de um psicólogo desempenhar a execução da atividade. A realização da entrevista ocorreu em um único encontro com cada participante e a duração foi de, aproximadamente, 40 minutos. As entrevistas foram gravadas, transcritas e armazenadas em arquivo no computador, mediante consentimento do entrevistado. As entrevistas foram transcritas na íntegra, para posterior categorização e análise dos dados. Estas seguiram o método de análise de conteúdo, como proposto por Bardin (2002), na qual se trabalha individualmente cada relato e em uma etapa posterior em seu conjunto; dessa forma, construíram-se as categorias Desenvolvimento do trabalho, 0 olhar de dentro do judiciário, e Resultado de um tempo de valorização da infância, as quais serão apresentadas na seção que segue.

\section{Resultados e discussões}

A análise de conteúdo permitiu identificar três eixos temáticos divididos em subcategorias, definidos e ilustrados por meio de trechos das falas dos entrevistados.

\section{Desenvolvimento do trabalho}

\section{Um trabalho em equipe}

No entendimento dos profissionais entrevistados, pode-se destacar uma percepção e funcionamento do DSD como sendo realizado num trabalho em equipe. Em suas falas, fica explícito o entrosamento entre os técnicos, as trocas de experiências e de informações sobre como colher o testemunho das crianças e adolescentes intimados.

... conversamos entre nós três sobre os casos... aqui o Serviço Social se entrosa bem com a Psicologia, que tem comarcas que não se relacionam bem, né? Mas aqui a gente se dá muito bem, a gente troca experiência, discute os casos, então é um trabalho em equipe mesmo... (Assistente Social 2).

\footnotetext{
2 Data da aprovação: 25 de agosto de 2009, sob o CAEE (Certificado de Apresentação para Apreciação Ética) 0085.0.243.000-09.
} 
... eu só acho assim que dentro da experiência que eu tenho assim com o Depoimento Sem Dano, o psicólogo, o assistente social, tô falando da ótica do efeito que dá, são pessoas que tem um preparo, pra poder conversar, pelo menos as nossas profissionais, aqui que fazem, fazem de uma forma muito preparada... (Juíza).

Os profissionais que desenvolvem a atividade proposta no projeto de lei têm clareza da importância da interdisciplinaridade para o seu desenvolvimento, as diferentes formas de abordagem sobre o assunto se complementam de acordo com o conhecimento que cada categoria profissional contempla. Esse entrosamento é percebido e aproveitado para execução do trabalho. 0 papel do psicólogo e do assistente social é bem explorado, principalmente no que se refere a abordar a vítima durante o testemunho.

Ao ouvir as opiniões dos profissionais entrevistados, perceberam-se algumas concordâncias com a literatura apresentada. No que tange à noção de que o DSD é desempenhado em um trabalho de equipe, Santos (2008) destaca que a oitiva de crianças/adolescentes em contexto judicial deve ser uma compreensão de mais ramos da ciência. 0 conjunto dos saberes de diferentes áreas de atuação torna o trabalho eficaz, rico e completo, expandindo-se entre diferentes visões.

Considerando o fato de o trabalho envolver a Psicologia, o Serviço Social e a área do Direito em sua execução, Ferrari (2009) afirma que trabalhar em equipe adotando uma postura interdisciplinar implica em respeito e confiança no trabalho do colega/parceiro. A existência de um consenso entre os profissionais a respeito de como foi desenvolver uma proposta alternativa para o depoimento de crianças/ adolescentes parece ter contribuído para que esses profissionais se unissem em sua execução, buscando juntos delimitar e estruturar esse trabalho.

\section{Treinamento e capacitacão}

Outro aspecto elucidado entre os entrevistados foi o recebimento de capacitação para o estabelecimento do projeto de lei nas comarcas regionais. Os profissionais expuseram que foram convocados a conhecer como era realizado o DSD; esse treinamento aconteceu para as três áreas envolvidas pelo projeto (Direito, Psicologia e Assistência Social). A capacitação baseou-se em explicar o que era o projeto, qual sua finalidade, a forma de abordagem da criança/adolescente, como aconteceria a colhida do depoimento e sua finalização.

... tem orientação em relação às perguntas, no momento do acolhimento, de tu saber como é as perguntas, assim em relação à vida da criança, como que ela é, tentar um pouco se apropriar assim do vocabulário dela, se vai na escola, se tem irmãs, como que é um pouco a vida familiar, pra ir deixando a criança à vontade e permitindo que depois ela relate livremente o que aconteceu, e se ficar duvidas fazer perguntas que permitam que ela relate e não perguntas prontas, então não induzir, não ferir... (Assistente Social 1).

... todos nós recebemos um $C D$, quando ele foi falado no Rio Grande do Sul, os juizes receberam uma capacitação do que é, como funciona, pra quê, como, quando, quem faz... (Juíza).

... como o acolhimento da criança quando chega, a gente vai explicar pra ela como que é, o que vai acontecer naquela sala, o porquê dela estar aqui, fala aos familiares a gente explica com vai ser, baixar a ansiedade né, depois vem o momento de fazer em si... (Psicóloga). ... ele [juiz] conduziu muito bem, ele deitou no chão, deu bolachinha, ele deixou a criança a vontade, e ele colheu o depoimento... mas aí ele me pareceu preparado pra isso e se dispôs a isso, então não ouve necessidade do equipamento, e ele conseguiu fazer... (Psicóloga).

... eu acho que tem todo um preparo e um cuidado, eu também não sou contra se os juízes da infância e juventude, assim como os das outras varas, forem preparados pra isso, eu não sou contra, acho que seria interessante também, a gente ser preparado pra isso... (Juíza).

No relato dos entrevistados pode-se perceber que a ideia do projeto de lei é englobar as três categorias profissionais para a execução da proposta. 0 exposto em suas opiniões parece não haver distinção entre quem irá colher o testemunho, mas a importância de como este profissional deve estar preparado para tal, independente de sua função no processo. A forma de como inquirir a vítima de abuso sexual também é levada em consideração; um objetivo que demostra ser importante antes de relatar sobre o abuso é perceber o estado emocional do depoente, por isso a sala é diferenciada, protegendo a vítima das "figuras" do processo. 0 profissional é orientado a inicialmente abordar como é a vida da criança e ou adolescente, fazendo com 
que se sintam importantes e respeitados, além de transmitir à criança/adolescente uma sensação de segurança em reinvocar um acontecimento doloroso. Em relação a esse aspecto, destacam-se as considerações de Willians com relação à importância da capacitação dos profissionais envolvidos, independente de a qual área profissional pertença, a fim de "não forçar a criança a falar".

Como todos os profissionais descreveram, foram convidados a participar de capacitação, puderam ouvir outros profissionais que já desempenhavam a proposta, e assistiram a uma audiência em que o DSD foi realizado. Cabe destacar também que, quanto à capacitação, os profissionais fizeram algumas críticas proque não teria contemplado as especificidades de cada área, não havendo um amplo debate com relação à essência da proposta e os efeitos de sua implementação, ficando a percepção de que:

... o processo, esse veio de cima para baixo... a gente começou a fazer com os dados e conhecimentos mais teóricos, né? que a gente tinha... (Assistente Social 2).

... já foi dado pronto a gente não poderia opinar teria que fazer, né? (Psicóloga).

... os juízes criminais eu sei que nem todos eles sabem o que é o Depoimento Sem Dano, porque o tribunal, ao fazer aquela capacitação naquela época, não fez essa capacitação com os outros juízes e isso gera problemas, né? (Juíza).

\section{0 olhar de dentro do judiciário}

Em seus relatos, pode-se perceber o entendimento de quem está "do lado de dentro" da dinâmica institucional em contraposição à percepção de profissionais que tecem críticas e controvérsias sem, no entanto, estar em contato direto com a realidade prática a qual a proposta do projeto de lei contempla. As opiniões discorreram pelo entendimento da necessidade de a criança poder prestar seu testemunho em um espaço diferenciado. Nestas opiniões, pode-se compreender a realidade vivida no contexto judicial:

... só quem conhece a dinâmica de funcionamento de um processo judicial e criminal, vai entender o porquê que o Depoimento Sem Dano é necessário... ela é ouvida de qualquer jeito, então ela pode ser ouvida em uma sala de audiência, onde vai estar um promotor, defensor do réu, juiz, até às vezes o próprio réu... e que vão fazer as perguntas mais assim... mais constrangedoras, e além dela se constranger de relatar tudo novamente, por mais que numa audiência o juiz limite as perguntas, e diga pra criança que não precisa responder, ela já ouviu aquela pergunta, e no Depoimento Sem Dano não... (Assistente Social 1).

... não é o mais adequado o projeto do Depoimento Sem Dano, mas dentro da realidade que nós temos, sabendo, por exemplo, que isso é instituído por lei, que está dentro do rito processual, essa criança vai ter que ser ouvida, por enquanto não pode ser judicializado o primeiro depoimento, se você não tem como mudar agora isso, então tu tem que trabalhar pra que ocorra da melhor forma possível, e não simplesmente dizer "não"... (Psicóloga).

Com relação às percepções dos profissionais entrevistados, contemplam-se as colocações de Trindade (2005) na defesa por um redescobrimento da vítima pelas instituições judiciais, com vistas a movimentar-se para colocá-la como sujeito ativo no processo de envolvimento legal, cujos danos provocados pelo delito (vitimização primária) devem ser reparados, não ampliando a revitimização (dano secundário) no contexto judicial. Diante dessas considerações apontadas pelos profissionais, contraponto com questões levantadas por Brito (2008), fica claro que os profissionais estão atentos para que se evite mais revitimizações. Dessa forma, o discurso dos profissionais envolvidos no estudo entra em concordância com as afirmações de Ferrari (2009), apontando para a revisão do sistema de acolhimento de vítimas de violência infantil, anteriores ao encaminhamento judicial.

Percebe-se que diante dessas opiniões que resumem a dinâmica judicial, e expõem a realidade em que esses profissionais desempenham suas funções, as críticas e argumentos contrários à execução do DSD não fazem menção quanto à obrigatoriedade do testemunho em juízo da criança.

\section{Avaliação da proposta}

Destacam-se os entendimentos da avaliação da proposta do projeto de lei para cada profissional:

... que de certa forma há alguma proteção se considerar a forma na qual era feita antes, a exposição dela é menor, mas se tu pegar só a questão psicológica não, por- 
que inclusive ela tem que produzir a prova pra ela mesma, que foi ela no caso que sofreu com a situação, vai ter que se sujeitar a relatar de novo isso depois de vários relatos que ela já fez, então aí eu acho que ela não protege sobre esse aspecto... a principio eu acho que protege só a questão do setting mesmo... (Psicóloga).

... o depoimento acaba minimizando, mas evitando o dano não existe, mas com essa escuta, quem trabalha na área criminal acaba pensando no Depoimento Sem Dano de uma maneira diferenciada, não só como um papel de um profissional, seja psicólogo ou assistente social, mas como uma ideia de pelo menos humanizar este momento que ela invariavelmente vai passar... (Assistente Social 1).

... eu acho que sim, que o Depoimento Sem Dano ele é um método absolutamente válido e que protege a criança, mas é o que eu digo, ele só vai ser absolutamente eficaz quando for executado desde o início... acho que o Depoimento Sem Dano tem que ser expandido, de tão bom que ele é... (Juíza).

É possível observar que os profissionais se mantêm críticos quanto à proposta do projeto de lei, apontam suas falhas; mas validam e reconhecem a tentativa de minimizar os efeitos jurídicos de ouvir crianças e adolescentes. Em contrapartida a essa posição, as manifestações contrárias à proposta, na qual se evidenciam questionamentos a respeito do projeto, concentram suas críticas em qual profissional realizará a atividade proposta; não se considera o estudo desenvolvido para reduzir a vitimização secundária, à qual crianças e adolescentes estão sujeitos quando intimados a depor judicialmente.

\section{As vantagens}

Algumas vantagens em realizar a colhida do testemunho das crianças/adolescentes nos moldes do projeto de lei foram destacadas:

... o Depoimento Sem Dano tem um valor sim.. Ouvir uma criança em sala de audiência por pessoas que não têm preparo nenhum é absolutamente prejudicial; a criança tem medo, a criança revive situações, ela é conduzida a responder coisas, e quem não tem o preparo induz a criança a responder, porque sempre vai tender a responder com o que o adulto quer ouvir, então a gente vê isso o tempo inteiro... (Juíza).
... então realmente a alternativa é tentar minimizar os efeitos, eu diria até que não é tanto em relação ao abuso em si, não revitimização, e sim como espaço de audiência, que não é agradável... já que é inevitável que a criança seja ouvida, por enquanto que a gente possa fazer uma situação de menos sofrimento, se é que é possível... (Assistente Social 1).

... dentro da questão psicológica, o que é favorável nesse sistema é que de fato a criança não vai se confrontar, de repente se estiver lá no corredor o suposto abusador, e ela não vai passar pelo constrangimento de estar digamos cara a cara com todos os operadores do direito... então, se nós considerarmos a questão de setting onde isso vai ser feito, eu penso que ela vai estar protegida sob esse ângulo... (Psicóloga).

Nota-se que os profissionais reconhecem e apontam vantagens na utilização do método do DSD, destacam os aspectos de como as vítimas podem ficar protegidas e evitar revitimização durante o processo judicial. Vale ressaltar que, enquanto a legislação permitir ou não judicializar o primeiro depoimento, faz-se necessária uma mudança na acolhida do testemunho nos casos de abuso sexual contra crianças e adolescentes. Porque, caso a abordagem ocorra de forma despreparada pelo profissional, a vítima é revitimizada. $\mathrm{O}$ foco principal da proposta do projeto é protegê-la não só no ambiente em que o testemunho é prestado, mas também considera a forma com que ele acontece.

\section{Um começo, e não um fim em si mesmo}

A visão dos profissionais no que diz respeito a um aprimoramento da proposta pode ser percebida a partir das alternativas relatadas pelos mesmos:

... eu penso: é um rito processual, ela precisa ser escutada, vai precisar ser escutada, eu penso que, se tiver que permanecer, o mais adequado então seria judicializar a primeira vez que ela vai fazer o depoimento... (Psicóloga).

... o depoimento dela inicial tinha que valer, mas como não é assim, e que mudanças nesse sentido demandam outras reformulações até nos códigos de processo crime, então a gente tem que entender essa limitação, né? E acho que tem que ser feito com pessoas que tenham mais habilidade, propiciar pra 
criança um momento mais tranquilo, que já vale, né? (Assistente Social 2).

... ele não é ideal porque não está sendo usado na primeira vez que a criança é ouvida antes do processo judicial, lá na delegacia, no conselho tutelar, isso seria o ideal... (Juíza).

O consenso, por parte dos profissionais, é evidente para que a proposta do projeto se estenda e desenvolva-se na primeira instância da denúncia de abuso sexual; os profissionais não tomaram a proposta como única, entendendo-a como um caminho dentro do sistema judiciário para humanizar e valorizar a palavra da criança/adolescente, que até então estava prestando seu testemunho como um adulto. Diante disso, as opiniões e entendimentos que esses profissionais apresentam podem contribuir para um aperfeiçoamento da prática do DSD.

\section{A prática psicológica em diferentes visões}

Em suas percepções, observou-se que devido ao conhecimento sobre o desenvolvimento psicossexual infantil, além do fato da formação focar mais aspectos sobre a constituição infantil, bem como, a ocorrência de um reconhecimento do trabalho do psicólogo dentro do judiciário, os sujeitos entrevistados entendem a importância do psicólogo nessa modalidade de atuação.

... que a psicologia tem sim a contribuir, que a formação permite e possibilita justamente oferecer esse espaço, essa acolhida mesmo, até mais que o serviço social... eu acho que a gente tem que ter conhecimento, por exemplo, no desenvolvimento psicomotor, e até mesmo no desenvolvimento psicossexual da criança, as etapas do desenvolvimento, né? Até pra ver em que momento aquela criança está... e que pode diferenciar assim naquele momento... (Assistente Social 1).

... eu acho que nosso trabalho é muito respeitado, uma demanda muito grande, então quer dizer que eles estão valorizando, então isso é bom, agora é a forma como tu vai fazendo, diferente de tu chegar 'não, porque é isso, é assado!', tu tem que ter um nível de conversação, disponibilidade e não 'não é porque não é!', tu tem que mostrar o porque que não é... (Psicóloga).

A relevância do papel do psicólogo e o espaço que foi conquistado dentro do sistema judiciário são ressaltados e confirmados pelos profissionais entrevistados. A ele é embutido valor de conhecimento acerca do processo de desenvolvimento infantojuvenil, e de como este desenvolvimento pode ser afetado e prejudicado diante do reconhecimento de que o abuso sexual foi cometido. Diante dessa opinião, ressalta-se em concordância com Williams (s/d) a importância de deixar claro que o lugar ocupado pelo psicólogo, dentro do sistema jurídico vigente, é resultado de um reconhecimento por parte do Judiciário quanto às especificidades de tal categoria profissional.

No reconhecimento da valorização do profissional psicólogo, soma-se o fato de que esta categoria baseia seu trabalho na palavra, o que abre um canal de comunicação para o discurso. Com isso, toda a categoria profissional deveria possuir um nível de conversação a respeito da execução do DSD no sistema judicial. Deveria também debater o que pode ser feito diante da realidade exposta nas opiniões dos profissionais que estão inseridos no contexto jurídico.

Com relação às críticas que consideram inadequada a contribuição de psicólogos para desenvolver tal prática a qual o DSD se destina, faz-se necessário destacar que não houve nenhuma referência para o fato de os profissionais da área $p s i$ terem uma formação diferenciada, voltada para a escuta de crianças e adolescentes. As referências a respeito da prática psicológica se limitaram em considerar o que Brito (2008) defendeu como uma confusão de papéis ou indiferenciação de atribuições, pois a proposta do projeto de lei solicita ao psicólogo que realize audiências e colha testemunhos.

\section{E o que dizer sobre as críticas/dissidências?}

A respeito do entendimento que os entrevistados fazem sobre a dissidência/crítica sobre o DSD; as opiniões se dividiram, e aqui se pode observar o olhar específico das diferentes áreas:

... quando eu ouço esse tipo de manifestação, eu remeto para uma coisa que é mais além, que é de se repensar toda a atuação da Psicologia dentro do Judiciário, porque o Judiciário é um espaço de cumprimento assim... porque nos também estamos assim submetidos as determinações né, eu vejo que não é mesmo uma entrevista clínica... (Assistente Social 1). 
... a gente aprende dentro do curso, principalmente voltada a área clínica que você não responde a demandas né, mas se você se propõem a trabalhar dentro da área judiciária, prestar uma assistência ao juiz, então isso decorre de uma demanda... as pessoas que vem aqui não vêm por livre e espontânea vontade, todos vêem por uma determinação judicial, eu enquanto psicólogo tenho que me dar conta disso... (Psicóloga).

Na visão apresentada pela psicóloga, parece estar clara a diferença do campo jurídico para o espaço clínico, diferenciando o papel exercido pelo profissional, diante da área na qual ele se propõe a desempenhar sua profissão. Ao ouvir a opinião de uma das assistentes sociais que compõem a equipe entrevistada, no que se refere às especificidades quanto ao campo de atuação profissional, observou-se concordância entre esta e a psicóloga.

... até tem a crítica, a questão da Psicologia, de ser no espaço clínico... mas não é espaço clinico mesmo! É um espaço, que mesmo pra nós assistente social também não é um espaço de entrevista... a gente busca uma empatia, faz um acolhimento mas pra que a criança fale o que ela tem que falar, gente entende o silêncio... mas precisa trazer elementos para o processo, e quando se tem claro isso é outro divisor, né? Então eu acho que a gente tem que ter a ideia do espaço em que está inserido, que é um espaço de correção... eu acho que isso é uma dimensão que a gente tem que ter na nossa prática... (Assistente Social 1).

Nota-se a compreensão dos profissionais entrevistados sobre o espaço conquistado pelo representante $p s i$, sobre como este está inserido e qual sua função dentro do contexto. É exposta a clareza de abordagem dos campos em que a Psicologia atua, sendo, nesse caso, uma demanda jurídica. Esta fornece o cumprimento de uma medida judicial, cabendo ao psicólogo respondê-la, bem como, oferecer todas as alternativas e argumentos dentro de sua especificidade para a tomada de decisão judicial. Na execução do DSD, é interessante destacar que independente do espaço em que os profissionais estejam locados é necessária a clareza do seu papel para que possa desempenhar sua função da melhor forma possível e oferecer subsídios para o enfrentamento e abordagem de colher o testemunho das vítimas abusadas.

A respeito da diferenciação das categorias profissionais dentro da execução do projeto de lei, o
Conselho Federal de Psicologia (2008) em seu manifesto parece não compreender que os profissionais inseridos nesse contexto apresentam capacidade em distinguir os campos de atuação, ou seja, o que difere uma prática clínica (terapêutica) da atividade jurídica. As argumentações dos profissionais e Conselhos que questionam seu estabelecimento parecem transparecer um "engessamento" da compreensão e potencial de crítica dos profissionais que estão exercendo o DSD. Essa limitação de visão compromete um possível diálogo e aproximação entre os grupos que apoiam a proposta do projeto com aqueles que a rejeitam.

\section{Resultado de um tempo de valorização da infância}

Durante a realização das entrevistas, os profissionais relataram a importância de ouvir a criança/adolescente. Os profissionais também abordaram como a proposta do projeto de lei poderia contribuir para mudar o olhar sobre as vítimas de abuso sexual, identificando que esse olhar ainda está impregnado de preconceito, tanto por parte da sociedade como dos demais profissionais envolvidos no contexto judicial. Pode-se perceber que os entrevistados destacam a proposta do projeto de lei como tentativa de reconhecer a criança/adolescente como seres de palavra, cabendo considerar a concepção de Eliachef (2007) sobre a representação da criança-vítima, que pouco a pouco ganhou espaço.

... eu acho que ouvir a criança é importante, porque ainda às vezes a vítima fica muito sozinha, ela ainda é desacreditada, seja uma pessoa da família que não acredita nela, ainda mais se o abusador é alguém próximo, que na maioria das vezes é... as contradições que por ventura venha apresentar... (Assistente Social 1).

... então ainda se tem essa visão de que as meninas possuem um grande poder de sedução, que os homens não resistem... e isso vem no momento do depoimento, vem no momento da audiência, e eles falam: 'mas ela usava roupa assim... mas ela fazia isso... mas ela fazia aquilo... (Assistente Social 1).

... tem psicólogos que questionam o porquê que ela como foi a própria vítima, vai ter que produzir a prova dela? Aí se tu pegares o ECA, no terceiro capítulo diz assim, entre alguns itens: 'em relação a criança e adolescente, igualdade na relação processual, podendo 
confrontar-se com vítimas e testemunhas, e produzir todas as provas necessárias em sua defesa. Então é um direito, consta aqui e é um rito processual dentro da área do Direito... (Psicóloga).

Com respeito ao Estatuto da Criançae Adolescente (ECA), o DSD seria uma possível forma de colocar crianças/adolescentes como sujeitos de direitos, garantindo o ato de testemunhar, percebendo-os como capazes, dentro de suas especificidades quanto ao desenvolvimento. Essa compreensão também é compartilhada por Williams (s/d), que interpreta a proposta do projeto de lei como forma de garantir os direitos de crianças/adolescentes nos tribunais, dando voz a eles quando estão tolhidos de seus direitos. Outro aspecto com que o DSD pode contribuir, segundo a visão dos entrevistados, refere-se à exigência do sistema judiciário de obter outras provas, além das materiais. Outra contribuição seria creditar a vítima, que ainda é estigmatizada por sua vida pregressa e culpabilizada pela ocorrência do abuso sexual.

... então ele [DSD] se faz necessário, e num outro ponto de vista também pela credibilidade à vítima, porque geralmente, nas audiências, há uma tentativa de desqualificar a vítima, ou de que por um comportamento pregresso justifica-se o abuso... então, acho que é uma oportunidade de mostrar para o agressor, e para de certo modo também para a sociedade, que não é bem assim... pra tentar colocar algumas coisas no lugar, do tipo: o adulto agiu errado, porque ele inverteu uma lógica, que é de cuidador... (Assistente Social 1).

Nessa categoria, ficam claras a função social e a repercussão que o projeto de lei pode representar na sociedade, sobre as diversas formas de violências cometidas contra crianças e adolescentes, sendo que, nesse caso, a violência sexual se apresenta impregnada de representações distorcidas. A execução do projeto, se realizado de forma cuidadosa, pode contribuir para a redução da estigmatização pela qual a vítima ainda é acometida, tanto pelos que a cometem, como para aqueles que se omitem. 0 projeto também pode corroborar para a valorização da palavra da vítima, oferecendo espaço para que essa palavra desencadeie uma ação contra quem a realizou e abrindo uma oportunidade para que a vítima seja reconhecida como vítima.

\section{Considerações finais}

Deve-se esclarecer que, no trabalho em questão, não se teve intenção de apresentar os resultados obtidos como generalizações dos profissionais que executam a proposta do projeto de lei, os dados obtidos nesse estudo retratam uma visão centrada em apenas uma, das muitas comarcas regionais onde a execução do DSD se realiza. Pesquisas relacionadas à busca de métodos de tomada de depoimentos alternativos, os quais levam crianças e adolescentes a não serem revitimizados quando têm de rememorar seu sofrimento no processo de produção de provas judiciais, são um campo relevante e fecundo para novas investigações e abordagens no campo da Psicologia.

Por intermédio da análise das entrevistas, percebeu-se que, independente das críticas/dissidências sobre o projeto de lei, a execução da proposta está acontecendo, o desenvolvimento do trabalho ocorre em equipe, desempenhado de uma maneira interdisciplinar. Sobre a avaliação da proposta do projeto de lei, a equipe entrevistada percebe o quanto é importante uma abordagem alternativa para escuta judicial de crianças/adolescentes vítimas de violência; mas apresentam-se críticos diante da maneira como o DSD vem se estabelecendo. Os entrevistados reconhecem que o projeto de lei necessita de aprimoramentos, não o conceituando como um fim, e sim o considerando como um desafio no enfrentamento da violência sexual infantil, bem como, forma de valorização da criança/adolescente dentro da dinâmica do sistema judiciário.

Em consideração às críticas/dissidências que a proposta do projeto de lei promoveu, os profissionais da Comarca onde se realizou o estudo percebem que as argumentações contrárias parecem não compreender a dinâmica e as especificidades do contexto jurídico para basear suas posições. Essa distinção de percepção evidenciou-se pelo fato de que os profissionais que integram a equipe percebem definidos os campos de atuação, bem como o papel e a especificidade do psicólogo dentro da proposta do projeto.

No desenvolvimento da pesquisa, ficou evidente que tanto os profissionais entrevistados como os estudiosos da proposta e os Conselhos Federais de Psicologia e Serviço Social preocupam-se em respeitar crianças e adolescentes vítimas de violência quando estes forem abordados pelo sistema 
jurídico vigente. No entanto, faz-se de extrema importância que se preze pelo diálogo entre as categorias profissionais, para que se possa avançar na busca por metodologias de inquirição alternativas e não revitimizantes; e para que se promovam transformações no olhar da sociedade sobre as crianças/ adolescentes que ainda sofrem violências sexuais; diminuindo, assim, preconceitos, estigmações e culpabilização impostas às vítimas.

\section{Referências}

Bardin, L. (2002). Análise de conteúdo. (Trad. Luis Antero Reto e Augusto Pinheiro). Lisboa: Edições 70.

Brasil, Estatuto da Criança e do Adolescente. Brasília, Secretaria Especial de Direitos Humanos, Ministério da Educação, 2005.

Brito, L. M. T. (2008). Diga-me agora... O Depoimento sem dano em análise. Psicologia Clínica, 20(2). Recuperado em 6 jul. 2009, de http://www.scielo.br

Cezar, J. A. D. (2008). Projeto Depoimento Sem Dano: Direito ao Desenvolvimento Sexual Saudável. Recuperado em 9 abr. 2009, de http://www.amb.com.br/docs/noticias/2008/projeto_DSD.pdf

Conselho Federal de Psicologia. (2000). Disposições sobre a realização de pesquisa em psicologia com seres humanos. Resolução CFP 016/2000. Brasília/DF.

Conselho Federal de Psicologia. (2008). Manifestação do Conselho Federal de Psicologia sobre o projeto de lei que trata do Depoimento Sem Dano. Recuperado em 9 abr. 2009, de http://www.pol.org.br/pol/cms/pol/ noticias/noticia_080409_932.html

Conselho Federal de Psicologia [CFP]. (2009). Falando sério sobre a escuta de crianças e adolescentes envolvidos em situação de violência e a rede de proteção. Recuperado em 15 jan. 2011, de http://www.pol.org. $\mathrm{br} / \mathrm{pol} /$ export/sites/default/pol/publicacoes/publicacoesDocumentos/livro_escuta_FINAL.pdf
Eliachef C. (2007). Todos vítimas? A propósito dos maus tratos com crianças. In S. Altoé. A Lei e as leis: Direito e Psicanálise. Rio de Janeiro: Revinter.

Ferrari, D. C. A. (2009). Depoimento Sem Dano. Recuperado em 21 set. 2009, de http://www.promenino.org.br/ Ferramentas/DireitosdasCriancaseAdolescentes / tabid/77/ConteudoId/69586aad-15ea-4884-af80461376afcf41/Default.aspx

Goodman, G. S. (2008). Crianças vítimas do sistema judiciário: Como garantir a precisão do testemunho e evitar a revitimização. In B. Santos \& I. B. Gonçalves. Depoimento Sem Medo: Uma cartografia das experiências de tomada de depoimento de crianças e adolescentes. São Paulo: Childhood Brazil.

Santos, B., \& Gonçalves, I. B. (2008). Depoimento Sem Medo: Uma cartografia das experiências de tomada de depoimento de crianças e adolescentes. São Paulo: Childhood Brazil.

Souza, J. (2007). Depoimento Sem Dano: O que você pensa sobre isso? Recuperado em 20 ago. 2009, de http:// www.crprj.org.br/noticias/2007/0424-depoimento-sem-dano-o-que-voc\%C3\%AA-pensa-sobre-isso. html

Trindade, J. (2005). Crianças e adolescentes vítimas de violência: Envolvimento legal e fatores psicológicos estressores. Revista do Ministério Público do Rio Grande do Sul Direito da criança e do adolescente uma abordagem multidisciplinar, 54, 243-264.

Turato, E. R. (2003). Tratado de Metodologia da Pesquisa Clínico-Qualitativa. Petrópolis: Vozes.

Williams, L. C. A. [s/d]. Manifesto em resposta ao posicionamento do CFP a respeito do Depoimento Sem Dano. Texto enviado pela autora em 23 jul. 2009 e publicado no site do Laboratório de Análise e Prevenção de Violência (Laprev) da Universidade Federal de São Carlos. Recuperado em 24 jun. 2013, de http:// defesa-hetero.blogspot.com.br/2012/11/psicologia-sem-ideologia-em-defesa-do.html\#.Uch0TzvMCW4 